Richard A. Detweiler

\title{
The great oak table Strengths of librarians and libraries
}

For this nal From the Inside column Ive deviated from the usual librarian-turnedadministrator author to ask Rick Detweiler, president of the Great Lakes College Association, to share bis thoughts on the future of academic libraries. His perspective is shaped by his presidency of Hartwick College, his interim presidency of the Council on Library and Information Resources, his tenure as dean of the Frye Leadership Institute and, in the last century, his teaching social psychology at Drew University to this ACRL President. Pamela Snelson, ACRL President

A prized possession in my home is a big oak table. A discarded library table picked up many years ago, sanded and varnished, it occupies the center of our home of ce.

This library table can be a real pain. Its middle name is inertia it is so heavy that it takes four people to move it. There is a crack down the middle, where decades ago the wood mightily resisted changes in heat or humidity, but ultimately the table warped and fractured and is impossible to repair. But the size of my library table makes it really useful for our work; there is plenty of room to spread things out and pile up tons of resources, a couple of computers, a printer, and more.

I do wonder whether it still makes sense to own this massive library table, yet it is a reminder of my long affection for libraries. My rst recollection is the Burbank children s public library, where I happily spent hours of my childhood; then the wonderful college library, where, as an undergraduate, I studied; and the Hartwick College library, where, as a college president, I could sneak into a remote corner and read as a getaway from the unceasingly incessant demands of the job.

However, in my re ections today, this library table also brings me a sense of sadness. I think of the fact that libraries a millennia ago were the true center of the university, since it was around a collection of precious written materials that the rst universities formed; today there are many questions as to the purpose and future of libraries. I think of my many friends who run libraries large and small, and the struggles they and their professional staffs have over their status, the value of the MLS, and the respect they often don $t$ get from faculty.

I think of the enormous energy that goes into trying to invent new roles for the librarian (e.g., information literacy specialist) and the library (e.g., the coffee house and the student support center) roles that are thought to be meaningful for the decades ahead, but which may well be temporarily valued and transitional in this time of rapid change.

I also feel a greater sadness because I recognize there are no small number of librarians who will be offended, even angered, by my observations about the state of the library and librarian.

But as a natural glass-half-full fellow, I don $t$ stay long with this melancholy. I begin to think about how this great oak library table a strong and positive symbol of the past of the library to me might become a

Richard A. Detweiler is the president of the Great Lakes Colleges Association in Ann Arbor, Michigan, e-mail: detweiler@glca.org

○ 2007 Richard A. Detweiler 
simile about possibilities for a strong library for the future.

\section{Strengths and weaknesses}

Like the strong oak library table, what are some of the strengths of today s library?

a staff that is highly organized, service oriented, creates effective process, and knows how to maintain systematic, structured, systems;

possession of some truly unique resources (special collections);

one of the largest spaces on the typical campus under the (collaborative) control of one person; a symbol of the learning community;

one of the largest budgets on the typical campus under the (collaborative) control of one person; and

a profession that produces a true generalist in this time of over-specialization.

Weaknesses (or, at a minimum, pressures libraries create for their host institutions), like the crack in my library table, must also be recognized. While no one library or librarian is characterized by all of these, those that come to mind are:

a highly constrained budget with little or no excess;

a budget that has demanded (though not always received) increases at a rate far greater than most other budgets because of the added costs of technology and the rapid rise in the cost of print and nonprint resources;

space issues, including unlimited demand for future added space due to the growing size of collections (because of the increase in available materials and frequent resistance to weeding among faculty), an orientation toward the creation and maintenance of physical space at a time when people are increasingly wanting to work on their own schedule and in spaces of their own choosing, distrust of off-site storage, and space that is, because of oor-loading requirements, relatively expensive to build;

a tendency to emphasize current ways of organizing knowledge, such as the orien- tation toward structured intellectual inquiry (e.g., systematic use of often discrete information resources with their own vocabularies and modes of inquiry) in a time when people inquire in Google-ized ways with unstructured common vocabulary and lack of distinction among information types; a tendency to defend legacies (e.g., the need to grow paper collections in a digital age), and the predilection to equate value with collection size and patron count, regardless of whether books ever circulate or people who walk in the front door ever use physical information resources;

an alliance with the least resourced and sometimes under-valued part of most institutions the humanities for whom the library is seen as the laboratory (the sciences are very laboratory and digital collection based, with the various social sciences somewhere between the sciences and humanities in their needs); and

a profession that lauds the generalist (e.g., the typical MLA prepared librarian) in an era when the specialist is most highly valued in virtually every other discipline (yes, this is both a strength and a weakness).

$\mathrm{Hmm}$, there is a challenge there. While neither list is exhaustive, the list of weaknesses challenges to be avoided or overcome is longer than the strengths. While advocates of libraries in the traditional sense might produce a longer list of strengths, in my experience, senior leadership in colleges and universities do often think that the weaknesses/challenges outweigh the strengths of libraries as currently con gured.

\section{Creating opportunities}

Are there ways to transform weakness into opportunity? If, for example, one did not try to maintain past practices, regardless of however valued and valuable they are, then, one could imagine:

capitalizing on the extensive staff competence in supporting intellectual inquiry;

capitalizing on the strengths of the generalist, particularly for the liberal education goals of American higher education; 
allocating time to new activities that support student and faculty information needs;

a (relatively) large budget that could be redeployed;

a large amount of space made available for new purposes; and

the opportunity to create new alliances with more powerful or resourced parts of the institution (ranging from the sciences to the interests of students in this consumer-driven higher education environment).

Can we add these transformed weaknesses to the list of strengths and begin to think differently about the future of the library and the librarian? Let me give one example (perhaps a too aggressive example) of how one might imagine future activities or programs, based upon a subset of library/librarian strengths:

1. a staff that is experienced in supporting intellectual inquiry;

2. the intellectual strengths of the generalist;

3. time for new, information-needs supporting activities;

4. budget and space for new activities; and

5. new alliances.

Imagine that we want to strengthen information seeking by today s contemporary inquirer a person who most likely turns to the Internet from wherever they happen to be sitting, at whatever time it happens to be. Let s make this anywhere/anytime activity the domain of the librarian who can capitalize on the above ve attributes in support of the inquirer. What kind of system might this inquirer actually want to have; a system that the librarian might invent and support? It could involve an inquiry tool that would a) provide a mechanism for focusing searches on information of known quality; b) access all information types (text, visual, auditory) with a single inquiry/inquiry tool; c) access all information sources (books, periodicals, etc.) with a single inquiry/inquiry tool; d) support natural language (full text) as well as structured inquiry (e.g., subject and author using disciplinary conventions). Finally and importantly, e) a living librarian, routinely working remotely from the inquirer, available 24 hours per day, who could directly look at the search being done by the inquirer (or group of inquirers) and provide guidance.

There is nothing revolutionary about that description it is an obvious way to improve the ability of inquirers to succeed at quality inquiries regardless of when and where they work. But what might be thought of as novel is the reconceptualization of the library/librarian there is no assumption of the work of the library being associated with a physical place nor of librarian support happening at a particular time.

Librarians are not the collectors and preservers of a de ned set of resources, but are creative collaborators in the process of inquiry. It doesn t say that to become information literate, one must come to classes run by librarians at particular times in the library. It doesn $t$ say that to access the expertise of a librarian, one must come to the library. It doesn t support gate counts nor the importance of having a Starbucks to encourage gate counts. It doesn t say that a purpose of the library is to support collaborative learning through group study space nor to have classrooms to encourage use of the physical space.

While it doesn t say a lot of the things that are currently conventional about the practice of librarianship, it does refer to ways that libraries/librarians can directly support the work of today s inquirer. It says that there is an opportunity to support the process of inquiry as people actually practice it by using some of the strengths of the library/librarian.

The moral to this story is not that this way of thinking about serving the inquirer is the right idea, nor that other purposes of the library are unimportant. The moral is that, from this writers perspective, libraries and librarians are too often yes, and people. Because they are supporting the systems and facades of the past, while si- 
multaneously trying to add a bit of the new, they are allied with neither the past nor the future; they are rarely seen as strong and sustainable advocates of the future of the institution. In this time of resource limits and challenge from virtually every stakeholder, courageous choices are necessary. If librarians are to play an active and constructive role in creating the future of their institutions, including their own future in supporting education and scholarship, then they must start with open-eyed examinations of their strengths and weaknesses, not an evaluation based on past or current habits, but on the competencies and weaknesses that underlie current practice.

I am reminded of an earlier era of computing, the mainframe days, when to use a computer one needed to go to the impressive campus computer center for access. Coffee and snacks were available. Various support of ces were located there and open for long hours. There were large areas with tables to facilitate group work, because we needed to be taught by each other as we learned. These centers were made anachronisms by personal computers, and became empty, even as the effectiveness of the tools provided by computers increased.

Personal computers didn $t$ make the physical library anachronistic, but the rapid growth of vast quantities of Internet-based anywhere/anytime information is a real challenge to libraries and librarians. Over the long term these challenges will not likely be addressed by increasing the noninquiry reasons for coming to libraries (e.g., coffee shops and group-study spaces), but by thinking in new ways about how libraries and librarians can serve the inquiring mind. These new ways should not be based on the current practices of libraries as places, but on the underlying competencies and strengths of the profession.

My great oak table, once designed for the reading room of a library and capable of holding tall stacks of books and periodicals, is no longer in that setting nor is it used for that purpose. It is now in my home of ce, where my most creative inquiry happens, and instead of holding up books and periodicals (though I will admit that it does hold up some of them), it is the base for my Internetconnected computers. While cracked and a bit warped, it serves todays new needs as effectively as it did yesterdays needs and indeed, supports a much more effective and ef cient process of inquiry today than it ever did in the past.

Where is the value in libraries and librarians? There are many and they are strong, and as previous CERL News columns have indicated, there are many ways to communicate them. But if the future of the library is to be strong, then librarians must demonstrate that they are moving beyond the past and making choices today that directly serve the needs of tomorrow s inquiring mind. $\nsim$
( Stepping through... cont. from page 358)

together for the bene $t$ of the educational process.

While there are potential barriers to effectively enacting many of the ideas brought forward at the forum, all of the sponsoring associations expressed a need to continue to work together and discuss collaborative issues on a national level. Presenting joint panel discussions at the major conferences of each organization and cross-organizational work through committees were major ideas expressed to potentially continue and expand the conversations started in Denver. Adding stakeholders, such as university presses and classroom faculty, to the mix can serve to broaden the discussions. Continuing the conversations begun in Denver through additional forums and online or face-to-face presentations and repositories of successful real world collaborative projects can ensure that all stakeholders step through the door opened by technological innovation for the bene $t$ of their individual institutions and the improvement of higher education. $\boldsymbol{z}$ 